\title{
Smart Room System Model Using a Microcontroller for the Efficiency of Campus Operational Costs
}

\author{
Robby Yuli Endra ${ }^{1}$, Ahmad Cucus ${ }^{2}$, Freddy Nur Afandi ${ }^{3}$ \\ \{robby.yuliendra@ubl.ac.id ${ }^{1}$, ahmad.cucus@ubl.ac.id ${ }^{2}$, freddsie@yahoo.com ${ }^{3}$ \} \\ Universitas Bandar Lampung, Zainal Abidin Pagar Alam St. No 26 Bandar Lampung ${ }^{123}$
}

\begin{abstract}
Internet of Things (IoT) is a concept that adopts an automatic control system or control that is done through a gadget. Currently the concept of IoT helps a lot in everyday activities. We sometimes forget to deactivate the electronic devices that have been used and the equipment is unwittingly active for 24 hours. That kind of conditions gives an impact on the cost of electricity bills that are increasing. It also disposes the resources of electric power. In this study it discusses how to make a smart room model using Arduino as a microcontroller. By adopting IoT concept, electronic device control is done automatically without a user having to press on / off button on an electronic device.
\end{abstract}

Keywords: internet of things, arduino, microcontroller, home automation, model smart room.

\section{Introduction}

Nowadays, efficient and sustainable energy usage is an urgent necessity that influences technology development in numerous areas (e.g. building, transport and energy production and conservation systems). In this context, emerging Smart Grid technologies have been developed to reduce the energy consumption of electric devices installed at home, to seek out the lowest rates and contribute to the smooth and efficient functioning of the electric grid. Although many Smart Grid devices today are commercially available, the limited service scalability, the complexity of configuration and the low usability prevent their mass adoption.[1]

The Smart Home concept is the answer to the demand of integration of smart appliances and systems in the human environment. It encompasses a rising number of devices, services, and applications that make people's life and everyday duties easier.[2]

The purpose of home automation is to support inhabitants in their daily lives via technological means. Areas of interest include security functions like access control and surveillance systems, resource management with regard to water and electricity, multimedia functions for ubiquitous content stream-ing, and comfort functions like light and heat management.[3]

Smart room consists of two words, smart and room. Carol L. Stimel in his book Building smart cities stated that smart is an adjective used informally to describe someone who is smart, intelligent, or generally responsive. It is clear that the way we use the word today to describe sensor-based devices is the result of our tendency to anthropomorphize a nonhuman system because it is our need to choose the best modifier for nouns. Redefining our culture and our 
society, intelligent technology greatly changes the way we interact with our friends, communities, transportation modalities, homes, offices, and even our bodies. [4]

This is based on what happens now at Universitas Bandar Lampung (UBL) Campus that all electronic devices in the classroom either lights, LCD projectors, and air conditioners are turned on even when the lectures have finished lecturing. In addition to reducing the life of these electronic devices, turning on all devices that are not used will increase the cost of electricity payments.

The solution for solving these problems is a smart room system model using Arduino microcontroller and several sensors such as PIR sensor, temperature sensor, and ultrasonic sensor.

The Arduino is basically an open-source electronics prototyping platform that is made up of two essential parts: the hardware, which is the Arduino board, and the software, the Integrated Development Environment (IDE). At the heart of every Arduino board is a Microcontroller Unit (MCU), a type of Integrated Circuit (IC) with a processor, embedded memory, and programmable I/O peripheral devices.[5]

Vailability of low-cost sensors and ubiquity of wireless networking technologies is changing the landscape of how consumers interact with their smart homes. There are at least three ways in which consumers will interact with their smart homes in the near future; (1) tangibly interacting with objects in the home through touch or by sitting on, for example,(2) by communicating with objects within the home using voice commands, and 3) by using body gestures.[6]

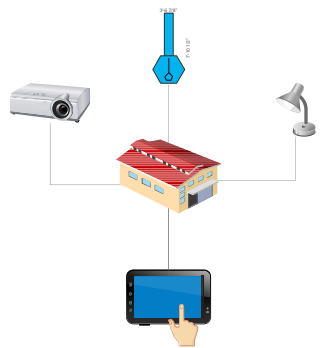

Fig. 1. Concept/model of Smart Room.

The purpose of this study was to create a smart room model with the concept of classrooms in the internet-based campus. in this automation uses several supporting tools such as Arduino, sensors, cameras for object detection.

\section{Related work}

This research was developed based on previous research entitled designing Smart Home Interfaces: Traditional vs Virtual Prototyping. the results and conclusions in this study are Smart home dan room It is accessible through Smart phones, Personal Digital Assistant devices, laptops and desktop PC.[1] Inparticular, it supports the following functionalities: (1) Displaying the instant power consumption of individual appliances and of the whole dwelling; 
(2)Comparing the historical consumption and eventually export it to an appropriate file format; (3)Calculating the consumption and therefore the cost of the selected configuration. (4)Identifying the optimal configuration, which requires minimum power consumption in both monetary and energy terms.

In another study entitled Systems and technologies for Smart Homes / SmartPhones: A study and comparison they compare how smarthome is based on arduino and Raspberry. the result is the Arduino Milrocontroller can be applied or used for small projects and low cost is one factor. RaspberryPI is used for large projects but the costs incurred are relatively higher. [7]

In another study mentioning that advanced sensor technology opens up great potential to ensure the comfort of life.[8]

to design a smart home in the initial stage is about the security of the system. this is a major challenge in designing software for Smarthome. [9] And another study entitled Design of Smart Home Security System using Object Recognition and PIR Sensor states that the security monitoring system based on Internet of Things technology uses Raspberry Pi 3, Arduino, PIR sensor, web camera and buzzer technology and incorporates human detection capabilities with HoG and SVM.[10]

From the review that has been discussed, there are several researchers who discuss smart home by using several arduino, raspberry and other technologies. and based on this we will develop and add some features that do not yet exist, both in terms of technology and in terms of cost efficiency.By designing the initial model of the smartroom, we hope to find system weaknesses before the system is implemented

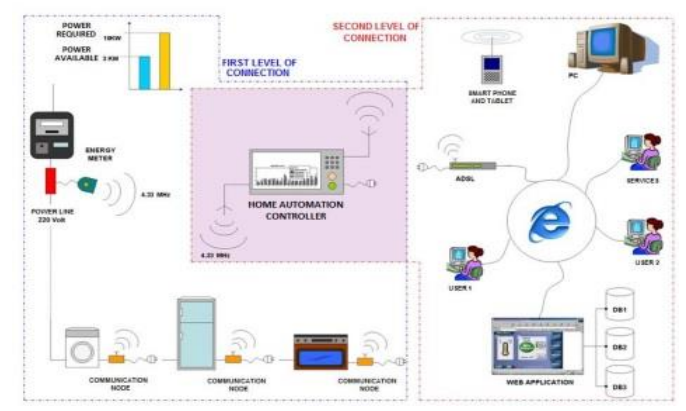

Fig. 2. The Homeline System [1].

\section{Methodology}

\subsection{Research Method}

In this study we used applied research where we focus on the application of the results of research conducted in the community to solve problems, not to focus on development and the impact that can be felt directly. Applied research is done with the aim of implementing, testing, and evaluating the ability of a theory to be applied in solving practical problems.[11]. 
Applied research is done a lot to solve practical problems of human life, and applied research usually refers to theories produced by basic research. Researchers who develop certain products have a purpose to solve existing and useful problems in people's lives.[12]

\subsection{Prototype Development Methods}

The development method Prototype is an iterative process in the development of a system where needs are changed into a working system which is continuously improved through collaboration between users and analysis. [13]

We chose the prototype development method because the results of the research were in the form of prototypes or models. Therefore the results of this model can be implemented properly.

\subsection{Modeling Smart Room Controller}

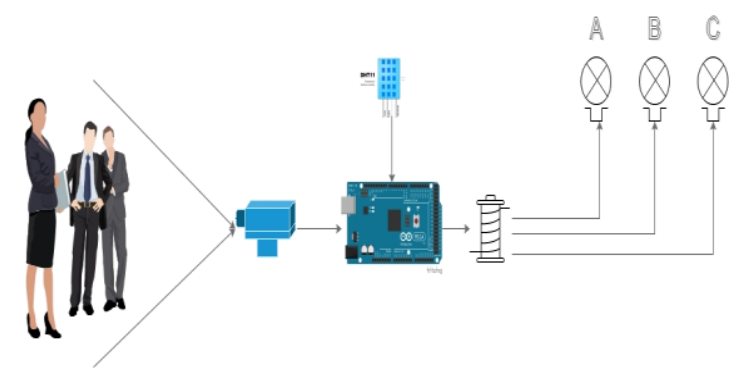

Fig. 3. Modeling of smart room controller.

The picture above is a control modeling that exists in this study, utilizing an Arduino Mega 2560 based on the ATMega microcontroller, a relay circuit that functions as a switch for electronic equipment, a camera used as an input tool in this study, and then an LED lamp, which represents each electronic equipment. The way this control system works is:

a. A person entering the room will be detected by the camera.

b. Furthermore, the input data results from the camera will be processed by Arduino, so that the output of the process is in the form of " 1 " and " 0 ", the output results are "1" and " 0 " because the relay recognizes the number " 1 " and " 0 " which means the number 1 connects the electric current, and the number 0 breaks the electric current.

c. The output from Arduino in the form of logic "1" and " 0 " will be sent to the relay.

d. The relay will flow through a weak electric current that flows through the coil, and changing the iron core will become a magnet and pull the soft iron anchor so that the contact will be connected and a strong electric current can flow.

e. Furthermore, the strong electric current will flow towards electronic equipment and activate electronic equipment.

f. And if the object cannot be detected by the camera, the light as an indicator does not turn on.

g. The control system through the temperature sensor will be active when there is an object detected by the camera. The temperature sensor will read the temperature in 
the room and send temperature data to the Arduino and then send logic 1 to the relay when the temperature is more than 250 Celsius and activate the lamp, as an initialization of Air Conditioner (AC).

\section{Results And Discussion}

\subsection{Design of Smart Room Prototype using Arduino Mega 2560}

Prototype design in this study uses Arduino Mega 2560 as Controlling center, and as a processor the output results from object detection and temperature and humidity sensors (DHT11). The output generated from Arduino Mega 2560 is an LED (Light Emitting Diode) lamp that lights up, representing every electronic device in the room such as a lamp, and air conditioner or Fan. Here's a prototype design picture:

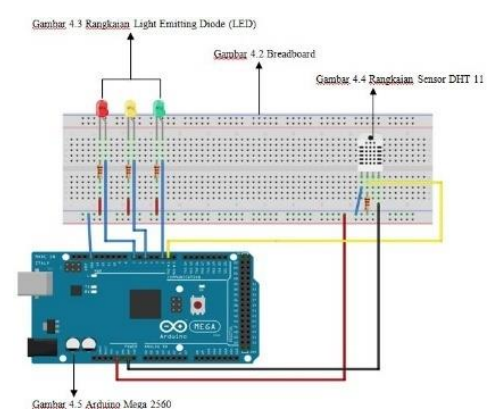

Fig. 4. Smartroom Model Architecture.

Each device used in this study is connected using a male-male jumper cable because each device has legs that have different functions. To connect all existing devices it requires Breadboard (Solderless board) so that all existing devices can be connected together.

DHT11 sensor is used as an indicator when the room temperature has exceeded the standard. The Air Conditioner or the fan will be active, and when the air temperature is too cold the air conditioner will turn off. Both conditions will run automatically with the help of Arduino because the data generated from DHT11 sensor is in the form of float data type. Data results will be sent simultaneously (continuously).

On Arduino Mega 2560 the float data type from the sensor is reprocessed into outputs in the form of 0 and 1 . When the output is 1 then the LED lamp 2 (representing the air conditioner) will be active, whereas if the output is 0 then the LED lights remain in the off condition. 


\subsection{Coding Controlling with Arduino IDE (Integrated Development Environment)}

In this study Software Arduino IDE (Integrated Development Environment) uses version 1.6.12, using Arduino IDE (Integrated Development Environment) that can embed commands into the Arduino Mega 2560 microcontroller. The following is the Arduino 1.6.12 interface:

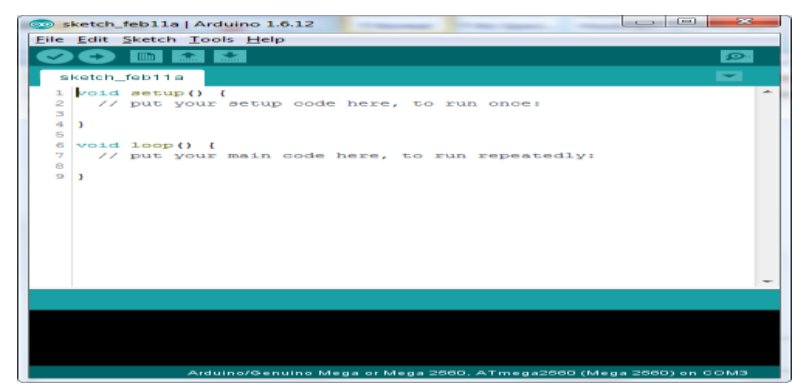

Fig. 5. Arduino IDE.

To embed the command into Arduino, we use the syntax in Arduino called Sketch.

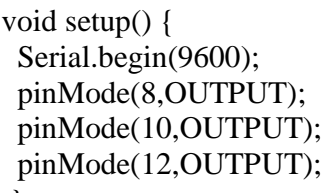

The following is the picture when compiling the sketch and verifying sketch made:

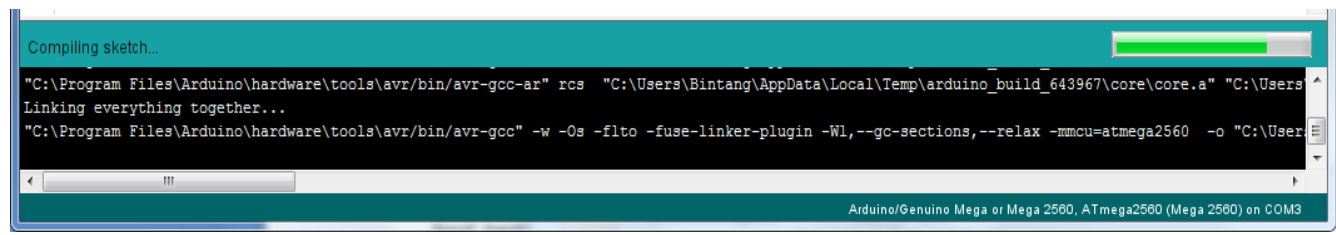

Fig. 6. Compiling Process, sketch, and verifying sketch.

\section{Conclusion}

In the research we can draw the conclusion that:

a) Control of electronic devices can automatically manage resources more efficiently.

b) A lamp can be activated automatically when an object (Human) is detected by the camera and can be switched off automatically when there is no object (Human) detected in the room such as the design in Figure 3.6 Modeling controlling smartroom. When the camera manages to detect the presence of an object (Human) it 
will automatically activate the DHT11 sensor as a temperature and humidity sensor that functions as an indicator to activate the B lamp.

c) And when there are more than 2 objects detected by the camera, it can activate the $\mathrm{C}$ Lamp.

d) The air conditioner can be activated automatically when the room temperature exceeds 250 Celsius, and will turn off automatically when the room temperature is below 170 Celsius.

\section{Acknowledgements}

We would like to thank the Chancellor of Bandar Lampung University and his staff who have fully supported our research process. As well as many parties who have supported this research both from a technical or technical aspect, which we cannot mention one by one. We hope our research becomes one of the scientific references in the field of computer science and is beneficial to society.

\section{References}

[1] S. Ceccacci and M. Mengoni, "Designing Smart Home Interfaces: Traditional vs Virtual Prototyping," Proc. 10th Int. Conf. PErvasive Technol. Relat. to Assist. Environ., pp. 67-74, 2017.

[2] J. M. Batalla, A. Vasilakos, and M. Gajewski, "Secure Smart Homes: Opportunities and Challenges," in ACM Computing Surveys, vol. 50, no. 5, 2017, pp. 1-75.

[3] J. Brich, M. Walch, M. Rietzler, M. Weber, and F. Schaub, "Exploring End User Programming Needs in Home Automation," ACM Trans. Comput. Interact., vol. 24, no. 2, pp. 1-35, 2017.

[4] D. Thinking, Building Smart Cities. 2016.

[5] M. Meruje, M. G. Samaila, V. N. L. Franqueira, M. M. Freire, P. Ricardo, and M. Inácio, "A Tutorial Introduction to IoT Design and Prototyping with Examples," pp. 153-189, 2018.

[6] W. M. Khan and I. A. Zualkernan, "SensePods: A ZigBee-Based Tangible Smart Home Interface,” IEEE Trans. Consum. Electron., vol. 64, no. 2, pp. 145-152, 2018.

[7] K. KARIMI and S. Krit, "Systems and technologies for Smart Homes/Smart Phones: A study and comparison."

[8] A. Schieweck et al., "Smart homes and the control of indoor air quality," Renew. Sustain. Energy Rev., vol. 94, no. June 2017, pp. 705-718, 2018.

[9] B. C. Chifor, I. Bica, V. V. Patriciu, and F. Pop, "A security authorization scheme for smart home Internet of Things devices,” Futur. Gener. Comput. Syst., vol. 86, pp. 740-749, 2018.

[10] N. Surantha and W. R. Wicaksono, "Design of Smart Home Security System using Object Recognition and PIR Sensor,” Procedia Comput. Sci., vol. 135, pp. 465-472, 2018.

[11] Sugiyono, Metode Penelitian Kuantitatif Kualitatif dan R\&D. Alfabeta, 2014.

[12] S. M. Azuar Juliandi, Irfan, Metodologi Penelitian Bisnis: Konsep dan Aplikasi. Medan: UMSU Press, 2014.

[13] H. al Fatta, Analisis dan Perancangan Sistem Informasi untuk Keunggulan Bersaing Perusahaan dan Organisasi Modern. Yogyakarta: Andi Yogya, 2007. 